\title{
OBJECTIVE STRUCTURED PRACTICAL EXAMINATION IN HUMAN ANATOMY AND PHYSIOLOGY PRACTICALS IN PHARM D CURRICULUM- A PILOT STUDY
}

\section{S. Arinnatania, M. Umamaheswari, A.T. Sivashanmugam, P. Jagannath, T.K. Ravi \\ College of pharmacy, \\ Sri Ramakrishna institute of paramedical sciences, \\ Sri Ramakrishna hospital campus, coimbatore-64l 044.}

- BACKGROUND: A single exam does not fullfill all the functions of an assessment in practicals. Hence, Objective Structured Practical Examination (OSPE) can be used to assess practical competencies in an appropriate, stepwise, methodical, objective and time-oriented manner with direct observation of the student's performance. This method was derived from Objective Structured Clinical Examination (OSCE) by Harden and Gleeson as an evaluation tool in early 1970's. The present study was undertaken in the Human Anatomy and Physiology practicals with the First year Doctor of Pharmacy (Pharm D) students at a private Pharmacy college. A set of 15 students were assessed using OSPE at 15 stations for a duration of 3 hours. The merits of OSPE include integration of knowledge, practical as well as communication skills with majority of the topics covered, transparent evaluation that covers most of the topics and was found to be student friendly. The demerits are, it requires planning, more number of examiners, time consuming and observers' fatigue.

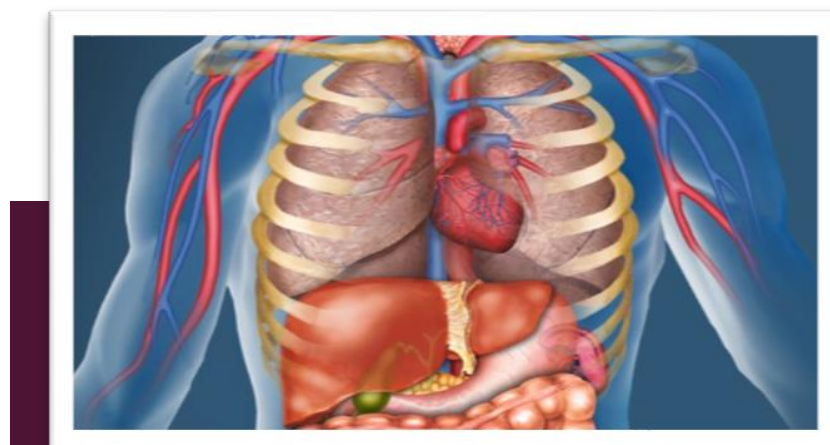

AIM AND OBJECTIVES: The present study was undertaken to determine the reliability and student satisfaction regarding OSPE as a method of assessment of laboratory exercises. The objective of the study was to determine first year Pharm D students' perception and performance in OSPE and comparison of their views on Traditional Practical Examination in Human Anatomy and Physiology practicals.

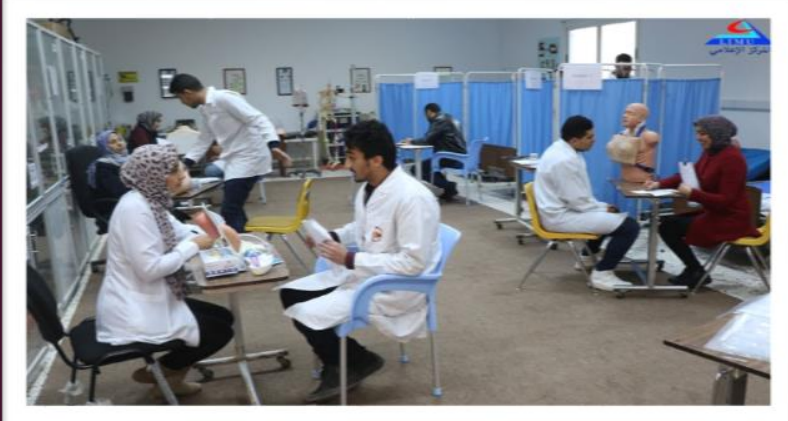

METHODS: A total of 15 students of First year Pharm D course in Human Anatomy and Physiology practicals were included for OSPE. Five teaching staff and 2 non-teaching staff were included in conducting OSPE. During the session, students were made to rotate through 15 stations out of which 5 stations were composed of questions that tested their knowledge and critical thinking (Response station) and 1 as Question station (viva voce) and 5 stations which were composed of skills that students had to perform before the examiner (Procedure station).
Four stations were kept as Rest stations. Performance of the students was assessed by specific scoring methods employed in various stations. The feedback from the students was used to compare OSPE with Traditional Practical Examination (TPE).

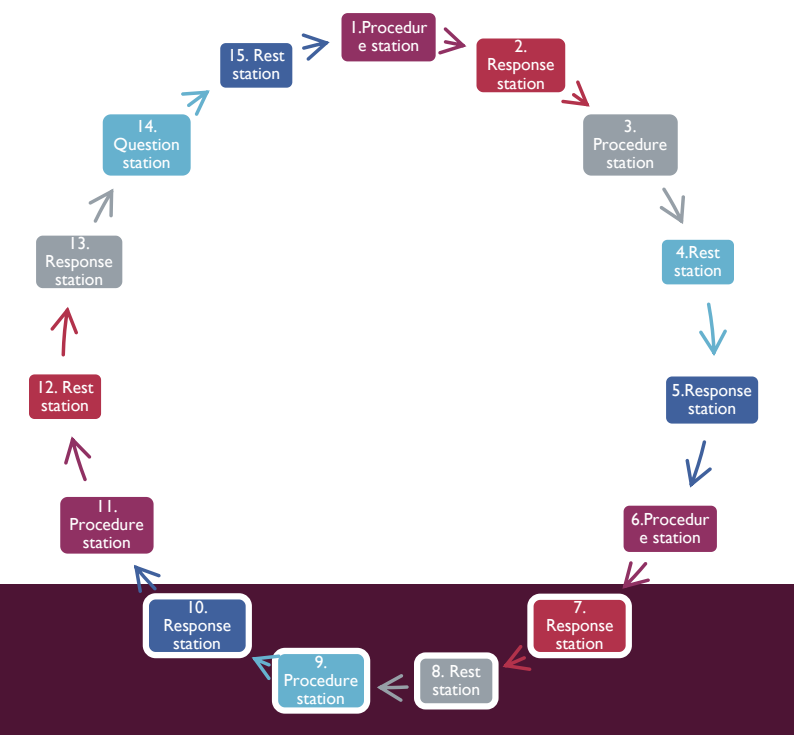

RESULTS: Results showed a positive perception of OSPE as a better way of assessment in a quick, fair and unbiased manner. Students indicated that the assessment using OSPE covered most of the topics and skill sets. Feedback from the students indicated that OSPE provided improvement and transparency in assessment and $90 \%$ of the student was in favour of OSPE. They felt the fear of facing the examiner relieved their anxiety.

\section{TRADITIONAL VS OSPE}

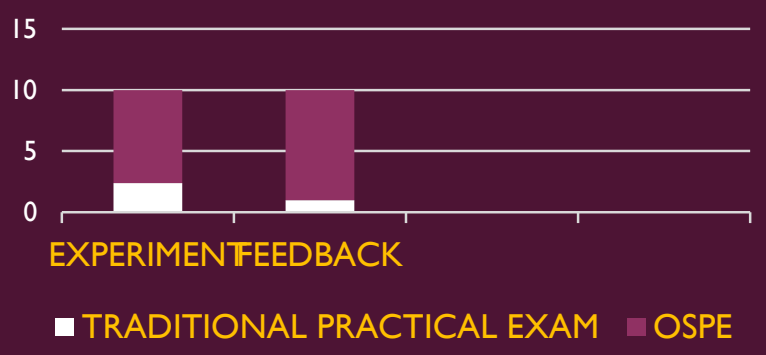

CONCLUSION: The students felt that the OSPE is an objective, unbiased and consistent mode of evaluation, deserving a place in Pharm D curriculum. 